\title{
O PAPEL DAS REDES ELETRÔNICAS NA CONSTRUÇÃO DO CONHECIMENTO EM AMBIENTE ACADÊMICO: MEIO OU FIM? ${ }^{1}$
}

\section{THE PAPER OF THE ELECTRONIC NETS IN THE CONSTRUCTION OF THE KNOWLEDGE IN ACADEMIC ENVIRONMENT: HALF OR END?}

\author{
Reginaldo de Jesus Carvalho Lima ${ }^{2}$ \\ Adelaide Maria Coelho Baeta ${ }^{3}$ \\ Neuza Maria Belo ${ }^{4}$
}

\begin{abstract}
RESUMO: O presente artigo aborda o tema "redes" e procura compreender o comportamento dos acadêmicos em relação ao uso da internet e seus recursos na construção coletiva de conhecimento. $\mathrm{O}$ objetivo é incentivar a reflexão crítica acerca da percepção e do uso que os acadêmicos da área de gestão têm feito desses recursos. Para tanto, propõe a análise dos seguintes aspectos: domínio de recursos tecnológicos; percepção da relevância da interação com outros atores; comportamento informacional. Fundamenta-se num Survey realizado no primeiro semestre de 2007, na região metropolitana de Belo Horizonte em Minas Gerais. A partir da aplicação de 550 questionários, foram inquiridos docentes e discentes de cursos com foco em gestão, nos níveis lato e stricto-sensu. A análise dos resultados revelou que, de forma geral, os acadêmicos pesquisados não priorizam a construção de arranjos destinados à produção coletiva de conhecimentos e, neste sentido, fazem uso restrito dos recursos tecnológicos.
\end{abstract}

PALAVRAS-CHAVE: Redes Eletrônicas, Conhecimento, Ensino Superior, Gestão, Docentes,

ABSTRACT: The present article approaches the subject "nets" and looks for to understand the behavior of the academics in relation to the use of the Internet and its resources in the collective construction of knowledge. The objective is to stimulate the critical reflection concerning the perception and of the use that the academics of the management area have made of these resources. For in such a way, it considers the analysis of the following aspects: domain of technological resources; perception of the relevance of the interaction with other actors; informational behavior. It is based on a Survey carried through in the first semester of 2007, the region metropolitan of Belo Horizonte in Minas Gerais. From the application of 550 questionnaires, learning professors and of courses with focus in management had been inquired, in the levels broad and stricto-sensu. The analysis of the results disclosed that, of general form, the searched academics do not prioritize the construction of arrangements destined to the collective production of knowledge and, in this direction, makes restricted use of the technological resources.

KEYWORDS: Electronic nets, Knowledge, Superior Education, Management, Professors.

\footnotetext{
${ }^{1}$ Artigo publicado no EnEPQ - I Encontro de Ensino e Pesquisa em Administração e Contabilidade - Recife / PE - 21 a 23 de novembro de 2007.

Artigo Recebido em 21.08.2008. Revisado por pares em 09.10.2008. Recomendado em 16.10.2008 por Denise Del Pra Netto Machado (editora). Publicado em 15.12.2008.

Organização Responsável pelo periódico: Universidade regional de Blumenau - FURB - www.furb.br/rn

${ }^{2}$ Mestre em Administração, Coordenação e Professor do curso de graduação em Administração - Faculdade de Ciências Exatas e Gerenciais (Faculdades Integradas de Pedro Leopoldo) - regilima@unipel.edu.br

${ }^{3}$ Pós-Doutora Université du Québec, Professora do curso de Mestrado Profissional em Administração - MPA das Faculdades Integradas de Pedro Leopoldo - FPL - regilima@unipel.edu.br

${ }^{4}$ Mestre em Administração, Professora das Faculdades Pitágoras - regilima@unipel.edu.br
} 


\section{INTRODUÇÃO}

No atual contexto, a sociedade busca novas perspectivas para analisar e compreender os fenômenos que afetam a realidade. Num quadro de instabilidade e complexidade, no qual as ciências pulverizam-se originando áreas específicas e reorganizam-se em novos campos do saber, o interesse pelo processo de criação do conhecimento ganha destaque. O governo, as comunidades científica e empresarial reconhecem que, para superar as mazelas e problemas sociais, fazem-se necessários múltiplos olhares da ciência e a construção coletiva de conhecimento. Neste sentido, o estabelecimento de parcerias e o estímulo à integração entre os diversos atores sociais tornam-se relevantes. Entretanto, diante de uma lógica que privilegia o individualismo e a competição, a criação de estruturas que favoreçam a troca de informações e a cooperação apresenta-se como um desafio. Cooperar e competir simultaneamente requer mudanças de comportamento, de percepção e de capacitações (MORGAN, 1996; TENÓRIO, 2000).

O estudo do tema "redes" instiga a compreensão dessa dinâmica e contribui para a visualização de esquemas que permitem o intercâmbio e a construção de conhecimento de forma colaborativa. Diversos autores destacam a importância das redes na configuração da sociedade contemporânea (CASTELLS, 1999; DAVENPORT, 1998; TERRA; GORDON, 2002). Nesses arranjos de aprendizagem, os integrantes podem obter informações e complementar o grau de conhecimento sobre determinado assunto.

A intensificação do uso de computadores, a ampliação do acesso à internet e o uso das novas Tecnologias e Informação e Comunicação (TICs) possibilitam uma revolução no processo de comunicação, favorecendo a criação, a manutenção e a ampliação dessas redes. Cortelazzo e Oliveira (1999, p. 115) destacam que "a comunicação eletrônica afirma-se de forma incontestável e irreversível”.

Em relação ao ambiente acadêmico que, pela própria natureza, vincula-se à criação e disseminação de saberes, o uso do computador, da internet e das TICs afetou a dinâmica da construção do conhecimento. Esses recursos permitiram amplo acesso às diversas fontes de informação, favoreceram o domínio sobre o registro e controle de dados e, sobretudo, contribuíram para a criação de um espaço virtual propício à aprendizagem e estabelecimento de relações com outros atores. Mas, afinal, considerando-se a intensa aplicabilidade e disseminação desses recursos, estarão os acadêmicos fazendo uso efetivo dos mesmos como ferramentas de aprendizagem? De que forma os têm utilizado na construção de relações que favoreçam a criação de conhecimento? Questões dessa natureza estimularam o estudo sobre o tema e a elaboração deste artigo, cujo objetivo é promover a reflexão sobre a atitude dos acadêmicos da área de gestão, em cursos de graduação e pós-graduação lato e stricto-sensu, em relação à utilização desses recursos na construção de redes informacionais ou de aprendizagem.

O estudo justifica-se pela necessidade de explorar como os "produtores" de conhecimento têm se posicionado diante da necessidade de buscar a construção coletiva de conhecimentos; analisar de forma crítica, ainda que breve, a aplicabilidade e o uso das TICs nas atividades acadêmicas e identificar os obstáculos que comprometem a expansão das relações de aprendizagem nesse meio. Bõhe, Silva e Zawislak (2004, p. 151) argumentam que "uma larga experiência em arranjos cooperativos pode ajudar a internalizar o saber sobre como realizar estes acordos com sucesso". Portanto, o estudo das conexões estabelecidas no meio acadêmico pode contribuir para a compreensão dos elementos e da extensão das redes que se constroem com a participação de atores externos. 
Como ponto de partida, adotou-se a seguinte questão: como os acadêmicos da área de gestão - professores e alunos - têm utilizado a internet e suas tecnologias na construção de relações orientadas à produção de conhecimento? No intuito de obter pistas capazes de favorecer a construção de possíveis respostas, procurou-se explorar a percepção dos acadêmicos acerca da necessidade de ampliar as redes de aprendizagem das quais participam, seu domínio sobre os recursos tecnológicos associados à internet e o comportamento que assumem na busca de conhecimentos. $\mathrm{O}$ artigo estrutura-se em cinco partes: esta introdução, que expõe o objetivo, as justificativas e algumas questões para reflexão; o referencial teórico, que apresenta os diversos conceitos; a metodologia; os resultados; e as considerações finais.

\section{REFERENCIAL TEÓRICO}

\subsection{Contexto e Ensino nas IES}

Nas últimas décadas, o panorama mundial foi afetado por várias transformações decorrentes de mudanças no cenário econômico-político. A intensificação da globalização associada à noção de aldeia global inibiu as barreiras entre diversos países e induziu, não raramente, o confronto de realidades adversas. Novos padrões culturais emergiram, enquanto a adoção de novos parâmetros para a avaliação de produtos e serviços remodelou o comportamento dos consumidores. Num mercado de elevada concorrência, a queda de demandas aniquilou empreendimentos. Todavia, determinados segmentos experimentaram significativo crescimento. No plano tecnológico, a associação das telecomunicações à informática possibilitou o avanço no campo das tecnologias de informação e interferiu profundamente nas formas de comunicação (LAUDON; LAUDON, 1999).

Configurou-se uma realidade caracterizada pela expansão de redes de informação e comunicação. Novas perspectivas de construção do conhecimento emergiram na sociedade informacional, ensejando, conforme Castells (1999):

\footnotetext{
uma forma específica de organização social em que a geração, o processamento e a transmissão da informação tornam-se as fontes fundamentais de produtividade e poder devido às novas condições tecnológicas surgidas nesse período histórico (CASTELLS,1999, p. 65)
}

Do ponto de vista desse autor, a economia global tem sido afetada pelo intenso uso de tecnologias e pela elevada capacidade de produzir, processar e veicular a informação numa estrutura conectada em rede. Nessa instabilidade e mudanças aceleradas nas quais as inovações tecnológicas são constantes, prevalece uma divisão tênue entre oportunidades de sucesso e fracasso. O conhecimento apresenta-se como fator determinante na redução de incerteza na tomada de decisão.

Em suas diversas formas, o conhecimento favorece a compreensão das variáveis que influem em determinado fenômeno, contribuindo para a gênese de soluções e avanços. Dessa perspectiva, as Instituições de Ensino Superior (IES) que assumirem a responsabilidade de "estimular a criação cultural e o desenvolvimento do espírito científico e do pensamento reflexivo" conforme determina a Lei das Diretrizes e Bases - LDB (1996, cap. IV, art. 43) desempenharão papel relevante no ensino e na produção científica. Trata-se de um desafio audacioso, sobretudo num contexto em que a prática reflexiva tem sido sufocada pelo imediatismo de perspectivas pragmáticas presentes nos diversos meios sociais. Conforme Ronca e Costa (2002, p. 24), a instituição que se propõe a oferecer ensino "precisa, obrigatoriamente, considerar o fluxo inovador de conhecimentos que afeta a formação e a pesquisa em geral". Nesse quadro complexo, conforme Morin (2002), o conhecimento 
permanece como uma aventura à qual a educação deve fornecer o apoio indispensável. $\mathrm{O}$ determinismo, não raramente, assinala de forma indelével as práticas e condutas de ensino, restringindo o pensamento crítico e a visualização dos fenômenos pela ótica da complexidade.

A análise das concepções de autores que adotam a abordagem crítica no ensino (ARROYO, 2001; DEMO, 1993; FREIRE, 1979; 2007; SAVIANE, 2003) e na gestão (MOTTA, 2001; RAMOS, 1984) apresenta possibilidades para ampliar o olhar sobre o processo de produção e disseminação de conhecimento. Torna-se necessário ressaltar que a criação do conhecimento, seja no âmbito individual ou organizacional, representa um processo de educação, de instrução e de novas atitudes perante a realidade.

Por diversas razões, como a disparidade de nível cultural e a heterogeneidade de perfil discente, as IES que ofertam cursos orientados à formação de gestores enfrentam diversos obstáculos no processo de ensino-aprendizagem. O perfil do futuro administrador representa um ponto crucial. A formação desse profissional deverá apresentar múltiplas competências e requer a superação do modelo tradicional de ensino. Aktouf (2005, p. 151) alerta para a reflexão que deve anteceder as ações formativas nas escolas de gestão e estabelece a necessidade de definir: o administrador "deve atender à mudança das coisas ou à sua reprodução?"

Em relação à realidade brasileira, são relevantes as considerações de Souza-Silva e Davel (2005, p.127) a respeito das práticas que orientam a formação de professor. Esses autores afirmam que predomina no país a visão de que a formação restringe-se à transmissão de conhecimento, uso de técnicas e instrumentos didáticos. Assinalam, ainda, que tais práticas indicam vínculos com "um modelo de absorção explícita de conhecimentos, apoiado na lógica tradicional-cognitivista de aprendizagem e formação". Segundo Paes de Paula e Rodrigues (2006, p.13), tem havido no país "escassas tentativas de recorrer à pedagogia crítica no ensino de Administração". A visão tradicional tem modelado a formação dos docentes e, por conseqüência, dos discentes. Estaria essa visão contribuindo para a modelagem de um comportamento passivo diante da produção do conhecimento? Considerando que as TICs podem favorecer a obtenção de informação e acelerar a aprendizagem, estariam os acadêmicos exercitando a construção do conhecimento de forma autônoma ou se comportando como autômatos?

\subsection{Redes e Tecnologia de Informação}

No que tange ao tema "redes", diversos autores propõem conceitos e tipologias distintas. Segundo Szarka (1990, p.10), uma rede é "um tipo específico de relação ligando um grupo definido de pessoas, de objetos ou de eventos". O autor categoriza as redes conforme sua finalidade, utilizando as expressões: redes de troca, destinadas às relações comerciais; redes de comunicação, que objetiva a troca de informação; rede social, que se constitui de elementos com vínculo afetivo. Julien (2000a, p.157) ao analisar a interação entre empresas, define redes como "outros atores econômicos com quem o empreendedor e sua organização mantêm relações para obter os diversos recursos" e adota quatro categorias: redes de negócio, cujos fins são comerciais; redes institucionais, que comportam as relações com órgãos governamentais, ONGs e instituições acadêmicas; redes pessoais, que se pautam em relações familiares e de amizade; redes informacionais, constituídas por contatos pessoais e institucionais para troca de informações e conhecimentos. Já Maillat e Kebir (1999) ressaltam que redes de troca relacionam-se às atividades de produção e comercialização, enquanto as redes de aprendizado dedicam-se ao intercâmbio de informações e conhecimentos. Neste trabalho adotou-se o conceito de redes informacionais proposto por Julien (2000a), que se 
apresenta mais adequado para o estudo proposto. Conforme esse estudo, as redes podem ser caracterizadas como instrumentos que promovem a troca de informações e a dinâmica de aprendizado.

Ressalta-se que, segundo Pinheiro (2003), as pesquisas envolvendo comunidades científicas e recursos eletrônicos representam um assunto recente, tendo se iniciado no Brasil em meados dos anos 1990. O estudo do envolvimento do acadêmico em redes de produção de conhecimento demanda a identificação dos canais de comunicação e intercâmbio utilizados, destacando-se, neste sentido, a internet e as TICs. Quanto à influência desses recursos nas diversas atividades, Castells $(1999$, p.43) faz menção ao profundo impacto das tecnologias da informação na estrutura social e afirma que "a tecnologia não determina a sociedade", mas considera "sua penetrabilidade em todas as esferas da atividade humana". Davenport (1998, p. 15) relata que a tecnologia da informação "poderá ser uma força poderosa para mudar o modo como fazemos nosso trabalho".

O uso da tecnologia digital e a transmissão por fibra ótica e satélite impulsionaram o avanço no campo das telecomunicações. A utilização de sistemas abertos, “... sistemas que utilizam padrões, comuns..." (O'BRIEN, 2002, p. 109) proporcionaram mais conectividade e interoperabilidade para o estabelecimento de redes computacionais. Conseqüentemente, esses avanços permitiram a base técnica para o estabelecimento da comunicação em rede. Tais avanços devem-se à interconexão entre computadores, possibilitada pela internet que, segundo Dizard (2000, p. 290), trata-se do "maior sistema inter-redes do mundo." Terra (2002) estabelece que a internet viabiliza a comunicação eficiente de pessoas com pessoas, de pessoas com máquinas, máquinas com máquinas. Para alguns autores, como Laudon e Laudon (1999) e Terra e Gordon (1998), as tecnologias associadas à internet favorecem as possibilidades de colaboração entre os indivíduos.

Em relação aos trabalhos acadêmicos e à produção de pesquisa, destacam-se os benefícios advindos do uso da internet, que permitiu o intercâmbio, em alta velocidade, de informações, imagens e sons em meio eletrônico. A utilização de artefatos como fóruns e blogs viabilizou a comunicação entre grupos específicos e o relacionamento entre públicos diversos.

Conforme Kumar (1997, p.28), "a troca de informações em todo o mundo entre estudiosos e especialistas também está se tornando rapidamente uma realidade". Numa perspectiva distinta, cuja ênfase recaia sobre as particularidades do estudo de gestão, Whitley (1984) alertou para a existência de fragmentação do conhecimento, já que sua produção ocorria na academia e nas organizações, e advertiu que essa separação restringia a formação de redes de cooperação. Para Wenger e Snyder (2000), a aplicação de tecnologias da informação revigorou estruturas colaborativas de produção de conhecimento. A disseminação de conceitos e a revitalização de arranjos como as Comunidades de Prática (CoP) deram origem a comunidades virtuais relacionadas aos mais variados temas. Cortelazzo e Oliveira (1999, p. 115) descrevem que "a comunicação eletrônica afirma-se de forma incontestável e irreversível" numa sociedade globalizada e caracterizada pela constante renovação dos saberes. Castells (1999, p.166) esclarece que "a internet e o correio eletrônico contribuíram para a formação de um sistema científico global" e afirma que "se não for global, a pesquisa científica da nossa era deixa de ser científica”.

\section{METODOLOGIA}

O presente estudo utilizou-se da realização de um survey. A população-alvo constituiu-se de docentes e discentes de cursos de Administração e Ciências Contábeis. Foram inquiridos acadêmicos de cursos de graduação e pós-graduação (lato-sensu e stricto-sensu) 
vinculados a uma IES particular que atua há mais de três décadas. Os cursos de graduação são oferecidos no período noturno, enquanto os de pós-graduação são diurnos. Os docentes pesquisados atuam em diversas IES distribuídas pelo estado de Minas Gerais, principalmente na região metropolitana de Belo Horizonte.

A amostra foi determinada a partir dos critérios de tipicidade e acessibilidade em conformidade com as considerações de Vergara (2003). Os dados foram obtidos da aplicação de um questionário, aprimorado por meio do pré-teste, estruturado a partir dos objetivos estabelecidos (GIL, 2002; VERGARA, 2005). Os conceitos utilizados por Souza-Silva e Davel (2005) e Pinheiro (2003) fundamentaram a pesquisa, representando a base para a construção do questionário, que foi constituído por três blocos de questões, totalizando 29 questões de múltipla escolha e duas abertas. O primeiro bloco destinou-se à caracterização do respondente e à obtenção de informações sobre o uso da internet e tecnologias associadas. $\mathrm{O}$ segundo bloco destinou-se a explorar a percepção dos acadêmicos sobre a construção de relações com os pares da instituição e parceiros externos. O terceiro procurou explorar o comportamento informacional dos acadêmicos. Foram aplicados 550 questionários impressos. Deste total, 30 não foram devolvidos e 17 foram desconsiderados na análise de dados, por terem sido invalidados durante o processo. Obteve-se, portanto, o retorno de $91 \%$. No intuito de garantir o anonimato, não foi solicitada a identificação do respondente.

A amostra foi composta de $10 \%$ de docentes da própria IES e $90 \%$ de discentes. Em relação aos docentes, $34 \%$ concluíram o mestrado ou doutorado e $66 \%$ cursos lato-sensu. Dos discentes, $20 \%$ estavam matriculados em cursos de pós-graduação, lato-sensu ou stricto-sensu e $80 \%$ estavam em cursos de graduação em Administração ou Ciências Contábeis. Um percentual de $44 \%$ dos respondentes era do sexo masculino e $56 \%$ do sexo feminino. Em relação à idade, $38 \%$ estavam na faixa etária de 17 a 25 anos, $36 \%$ de 26 a 34 anos, 15\% de 35 a 43 anos e 11\% acima de 43 anos. Em relação aos cursos de graduação, 39\% dos respondentes já estavam matriculados no curso há pelo menos dois anos, enquanto $71 \%$ já estavam no curso há pelo menos um ano.

A análise dos dados também se fundamentou na consistência teórica e nas referências conceituais que configuraram a base para a construção do escopo da pesquisa e do questionário. Esse procedimento teve por objetivo propiciar às diversas fases do trabalho organicidade e abrangência, de acordo com as considerações de Yin (2005). Os dados foram analisados de forma estruturada e sistemática. Utilizou-se da combinação de métodos distintos, conforme a classificação de Collins e Hussey (2005). Foram adotados métodos quantitativos informais, com a aplicação da contagem de freqüência e escalas de graduação na categorização dos dados e "procedimento analítico geral".

\section{RESULTADOS}

Em relação ao local utilizado com mais freqüência pelos acadêmicos para acessar a internet, $47 \%$ dos respondentes citaram o local de trabalho; 35\% mencionaram a própria residência; e o restante (18\%) indicou outras fontes, como escola, lan house e casa de parentes ou amigos. Sobre a freqüência de acesso, 73\% afirmaram acessar diariamente a internet e os demais $27 \%$ pelo menos um acesso por semana. Quanto às finalidades de uso, $87 \%$ afirmaram utilizar a internet na realização de atividades acadêmicas. Desse percentual, 49\% mencionaram o uso para fins didáticos e de aprendizagem e $31 \%$ para comunicarem-se com outros alunos e professores. Foi solicitado aos respondentes que, a partir de sua percepção, classificassem as tecnologias associadas à internet numa das seguintes categorias "irrelevante", "pouco relevante", "relevante" e "muito relevante". As respostas revelaram que 
a lista de discussão e IRC (chats e troca de arquivos) foram consideradas "relevante", enquanto a teleconferência e salas virtuais com fins acadêmicos foram consideradas "pouco relevantes". Foram 38\% os que afirmaram utilizar esses recursos de forma ativa para transmitir e receber informações. Acerca da utilização de serviços e produtos eletrônicos na construção de conhecimentos científicos, as seguintes alternativas foram consideradas "relevantes": base de dados; bibliografias em meio eletrônico; sites de eventos; e aquisição de publicações.

Em relação ao envolvimento dos acadêmicos de cursos de Administração e Ciências Contábeis em atividades de pesquisa, embora $52 \%$ dos respondentes mencionem que o envolvimento em pesquisas é essencial para a formação, quando perguntados sobre a utilização de teleconferências e salas virtuais com fins acadêmicos, os respondentes classificaram esses recursos como pouco relevantes; $18 \%$ afirmaram que a construção da identidade profissional está relacionada às ações e à vivência no mundo do trabalho e não ao envolvimento em atividades de pesquisas; $15 \%$ afirmaram que os acadêmicos deveriam envolver-se em comunidades de pesquisa; e 15\% concordaram que em cursos de gestão as atividades de pesquisa são secundárias, afirmando que o essencial é focar a aquisição de conhecimentos e técnicas validadas pelo mercado de trabalho. Observou-se que $48 \%$ dos pesquisados afirmam que o ensino de Administração e Ciências Contábeis deve objetivar a reprodução de conhecimentos validados pelo mercado

Em relação à importância atribuída à disciplina a partir de sua natureza, os resultados indicaram que: 56\% elegeram as disciplinas técnicas como as mais importantes para a formação; 39\% consideraram que disciplinas técnicas e humanísticas têm a mesma importância; e 5\% elegeram as disciplinas humanísticas.

Quanto à importância da integração dos acadêmicos com outras áreas do conhecimento, $77 \%$ consideraram importante essa iniciativa, enquanto $23 \%$ afirmaram não ser importante. As áreas citadas com mais freqüência foram: Economia, Direito, Psicologia, Informática. Essa resposta revelou o interesse na aproximação com outros campos do saber, no intuito de ampliar o contato com outras áreas. Todavia, a questão não se referiu à propensão de construção de relações neste sentido. Foram citados como principais fatores prejudiciais à integração com profissionais de outras áreas: falta de tempo e individualismo. Sobre a integração com atores externos, 67\% consideraram que "é responsabilidade da IES criar alternativas para que os discentes tenham contato com agentes externos."; enquanto 33\% consideraram que "é obrigação do aluno buscar a inserção em comunidades acadêmicas externas."

No tocante à utilização de outras fontes, além da sala de aula, para complementar o nível de conhecimento, $52 \%$ dos respondentes afirmaram que às vezes utilizam outras fontes; $35 \%$ afirmaram utilizar freqüentemente outras fontes e $13 \%$ afirmaram não utilizar outras fontes. O principal motivo mencionado foi "falta de tempo".

Em relação aos materiais escritos em língua estrangeira, 69\% dos acadêmicos declararam não consultar esse tipo de material, em função da falta de domínio do idioma; $26 \%$ afirmaram consultar "às vezes" e 5\% consultam com freqüência. Considerando o estabelecimento de relações com alunos, pesquisadores e docentes de outra instituição, $63 \%$ dos respondentes não interagem com quaisquer desse atores, 31\% mantêm algum tipo de relação "às vezes" e $6 \%$ frequentemente interagem com eles. Apenas 14\% afirmaram participar de algum grupo de pesquisa, dos quais $36 \%$ participavam de grupos de outras IES. Os resultados revelaram que, de forma geral, os acadêmicos, sobretudo os discentes, apresentam reduzido envolvimento em atividades de pesquisa.

Foi-lhes solicitado que indicassem os órgãos relacionados aos campos científico e profissional que conheciam, cujos resultados foram: $1^{\text {o }}$ - Conselho Regional de Administração 
(CRA) e Conselho Regional de Contabilidade (CRC); $2^{\circ}$ - Associação Nacional dos Cursos de PósGraduação em Administração (ANPAD); $3^{\circ}$ - Conselho Nacional de Desenvolvimento Científico e Tecnológico - CNPq.

Uma parcela equivalente a $15 \%$ dos respondentes afirmaram não conhecer as seguintes instituições: CRA, CRC, ANPAD, ANGRAD, FAPEMIG, CNPq. Em relação aos órgãos com os quais os acadêmicos estabeleceram contato, ao longo dos últimos 10 meses foram classificados conforme a seqüência: $1^{\circ} \mathrm{CRC} ; 2^{\circ} \mathrm{ANPAD} ; 3^{\circ} \mathrm{CRA} ; 4^{\circ} \mathrm{CNPq} ; 5^{\circ}$ FAPEMIG; $6^{\circ}$ ANGRAD.

\section{CONCLUSÕES}

A partir dos resultados, tornou-se possível tecer algumas considerações sobre a postura adotada pelos acadêmicos pesquisados em relação à utilização da internet e das tecnologias a ela associadas. Observou-se que eles têm tido acesso à rede em vários locais, entre os quais se destacaram o trabalho e a residência. De fato, a adoção das tecnologias computacionais pelas organizações vem possibilitando a uma parcela significativa de indivíduos ter contato com esses recursos no ambiente profissional.

Os resultados evidenciaram que a maioria dos acadêmicos pesquisados utiliza a internet diariamente. A aplicação do recurso tem ocorrido na realização de atividades de caráter acadêmico, mais especificamente para troca de material didático e comunicação via $e$ mails. Por outro lado, a barreira lingüística revelou-se um obstáculo à consulta de fontes estrangeiras.

Quanto à percepção dos acadêmicos sobre o envolvimento em redes de cooperação e produção de conhecimento, tornou-se evidente que uma parcela considerável (30\%) não reconheceu a importância das atividades de pesquisa sobre sua formação. Uma possibilidade de justificar o fato seria o argumento de que uma determinada parcela de discentes busca na academia apenas a formação para conquistar uma colocação imediata no mercado de trabalho, não lhes interessando atividades de natureza mais complexa. A declaração explícita de uma parcela de respondentes, equivalente a 15\%, acerca da preponderância das técnicas validadas pelo mercado de trabalho sobre as atividades de pesquisa, reforça esse ponto de vista. Esse fato torna-se crítico por se tratar de um público cuja formação deveria se caracterizar pela orientação com vistas à produção de conhecimento. Parece dominar a ênfase na formação reprodutora de conhecimento. Considerando a interação com outras instituições, destacaramse os órgãos de caráter profissional. As instituições de fomento e incentivo à pesquisa não ocuparam posição relevante.

Embora os acadêmicos reconheçam a importância da interação com outros campos do conhecimento, principalmente com as áreas de ciências sociais aplicadas, declaram obstáculos à interação, como o individualismo, a falta de tempo e o desconhecimento sobre das demais áreas. Faz-se necessário destacar que a maioria (67\%) dos acadêmicos pesquisados acredita que é função da IES estabelecer canais seguros para viabilizar o diálogo com o meio social.

Os acadêmicos, de forma geral, não interagem com os de outras IES, nem participam de atividade de pesquisa. Vale ressaltar que $75 \%$ dos respondentes são discentes dos cursos noturnos. Nessa condição, uma parcela considerável trabalha durante 0 dia e, conseqüentemente, tem tempo reduzido para empregar em atividades extraclasses.

A partir da análise dos resultados, tornaram-se mais claros alguns aspectos sobre a postura adotada pelos acadêmicos da área de gestão no processo de produção de conhecimento. O público pesquisado revelou possuir domínio do uso da internet e conhecimento acerca das TICs. Todavia, o emprego desses recursos na realização de 
atividades de natureza acadêmica restringiu-se à troca de e-mails e material informativo. As atividades de pesquisa foram consideradas secundárias, com pouca utilidade no processo de formação. Essa concepção, entretanto, pode ter sido influenciada pelos esforços limitados de estímulo à pesquisa, observado de forma geral, sobretudo nas IES de natureza particular. Isto fica bastante evidente na fraca relação com agências de fomento à pesquisa científica.

$\mathrm{O}$ exame de alguns aspectos do comportamento informacional dos acadêmicos merece reflexão cuidadosa, visto que os respondentes afirmaram que utilizam a internet com freqüência para aprimorar o nível de conhecimento. Todavia, uma análise do conjunto de respostas não indica postura ativa orientada à construção coletiva de conhecimento. Em relação à questão inicial proposta neste trabalho, "como os acadêmicos da área de gestão professores e alunos - têm utilizado a internet e suas tecnologias na construção de relações orientadas à produção de conhecimento?", conclui-se que esses recursos têm sido utilizados de forma automática como fins em si mesmos e não como vias para a construção de relações com outros atores. Nesse sentido, os respondentes demonstraram que tais recursos representam ferramentas para executar atividades de comunicação e troca de materiais dentro de esquemas fechados. Não se evidenciou o uso para criar espaços virtuais ou simplesmente expandir o número de atores envolvidos nas redes informacionais. Apesar de dominarem o uso, os acadêmicos não visualizam a importância do estabelecimento de relações com outros agentes. Esse fato pode ser ocasionado pela conjunção de diversos fatores, desde as influências de uma cultura individualista até a herança de um modelo de ensino pautado no tradicionalismo. È possível imaginar que a reversão desse quadro implica esforços consideráveis por parte das IES, dos órgãos governamentais e da própria sociedade.

\section{REFERENCIAS}

AKTOUF, O. Ensino de Administração: por uma pedagogia para a mudança. Organização e Sociedade, Salvador, v. 12, n. 35, p. 151/159, out./dez., 2005.

ARROYO, M.G.O. Ofício de mestre. Imagens e Auto-imagens. Petrópolis: Vozes, 2001. $250 \mathrm{p}$.

BÕHE, D.M.; SILVA, K. M.; ZAWISLAK, P.A. Rumo a uma estratégia de desenvolvimento de redes de PMES. Organização e Sociedade, Salvador, v. 11, n. 350, p. 147/166, mai./ago., 2004.

BRASIL. Lei de Diretrizes e Bases da Educação Nacional. Lei no 9394, de 20 de dezembro de 1996. Estabelece as diretrizes e bases da educação nacional. Brasília, DF, 1996.

CASTELLS, M. A sociedade em rede. $6^{\circ}$ ed. Tradução de Roneide Venâncio Majer. São Paulo: Paz e Terra, 1999. 698 p.Título original: The rise of the network society.

COLLIS, J.; HUSSEY, R. Pesquisa em Administração: um guia prático para alunos de graduação e pós-graudação. Tradução: Lúcia Simonini. 2. ed. Porto Alegre: Bookman, 2005. 349 p.

CORTELAZZO, I.B.C.; OLIVEIRA, V.B. Telemática: proposta e desafio à educação e comunicação. In: Vera Barros de Oliveira (organizadora), Informática em Psicopedagogia. 2. ed. São Paulo: Editora SENAC, 1999, p. 111-130. 
DAVENPORT, T.H. Ecologia da informação: por que só a tecnologia não basta para o sucesso na era da informação, Tradução de Bernadette Siqueira Abrão. São Paulo: Futura, 1998. Original: inglês.

DEMO, P. Desafios Modernos da Educação. São Paulo: Cortez, 1993. 272 p.

DIZARD, W. A nova mídia: a comunicação de massa na era da informação. $3^{\circ}$ ed. Tradução de Edmond Jorge, Rio de Janeiro: Jorge Zahar Ed.,2000. 324 p. Título original: Old Media, New Media: Mass Communications in the Information Age.

FREIRE, P.. Educação e mudança. 29 ed. Rio de Janeiro: Paz e Terra, 1979. 79 p. Pedagogia da autonomia: saberes necessários à prática educativa. 35 ed. São Paulo: Paz e Terra, 2007. 148 p.

GIL, A.C. Como elaborar projetos de pesquisa. 4. ed. São Paulo: Atlas, 2002. 171 p.

JULIEN, P.A. L'entrepreneuriat au Québec - Pour une révolution tranquille entrepreneuriale 1980-2005. Montreal, Les Éditions Transcontinental et Les Éditions de la Fondation de l'entrepreneurship, 2000a.

KUMAR, K. Da sociedade pós-industrial à pós-moderna: novas teorias sobre o mundo contemporâneo. Tradução de Ruy Jungmann, Rio de Janeiro: Jorge Zahar Ed.,1997. 258 p. Título original: From Post-Industrial to Post-Modern Society New Theories of the Contemporany World.

LAUDON, K.C; LAUDON, J.P. Sistemas de informação com Internet. $4^{\circ}$ ed. Tradução de Dalton Conde de Alencar, Rio de Janeiro: LTC, 1999. 389 p. Título original: Information Systems on the Internet: A problem- solvin approach.

MAILLAT, D.; KEBIR, L. "Learning Region" et systèmes territoriaux de production. Revue d'Économié Régionale et Urbaine, v. 3, p. 430-448, 1999.

MORIN, E. Os sete saberes necessários à educação do futuro. 5 ed. São Paulo: Cortez, Brasília, DF: UNESCO, 2002. 118 p.

MOTTA, F.C.P. Teoria das Organizações: evolução e crítica. 2 ed. São Paulo: Thomson Pioneira, 2001. 113 p.

O'BRIEN, J.A. Sistemas de informação e as decisões gerenciais na era da Internet. $9^{\circ}$ ed., Tradução Cid Knipel Moreira, São Paulo: Saraiva, 2002. Título original: Introduction to information systems.

PAES DE PAULA, A.P., RODRIGUES, M.A. Pedagogia Crítica no Ensino da Administração: desafios e possibilidades. Revista de Administração de Empresas, São Paulo, v. 46, Edição Especial Minas Gerais, p.10-22, 2006.

PINHEIRO, L.V.R. Comunidades científicas e infra-estrutura tecnológica no Brasil para o uso de recursos eletrônicos de comunicação e informação na pesquisa. Ci. Inf. Brasília, 
v. 32, n. 3, p. 62-73, set-dez, 2003. Disponível em www.ibict.br/cienciadainformacao Acesso em 20 de abril 2007.

RAMOS, A.G. Modelos de homem e teoria administrativa. Revista de Administração Pública, v. 18, n.2, p. 3-12, 1984.

RONCA, A.C.C., COSTA, R. $\boldsymbol{A}$ construção de uma democracia cognitiva., São Paulo em Perspectiva, 16(4): 24-29, 2002.

SAVIANE, D. Pedagogia Histórico-Crítica: primeiras aproximações. 8 ed. São Paulo: Autores Associados, 2003, 153 p.

SOUZA-SILVA, J.C.; DAVEL, E. Concepções, Práticas e Desafios na Formação do Professor: examinando o caso do ensino superior de Administração no Brasil. Organização e Sociedade, Salvador, v. 12, n. 35, p. 113-134, out./dez., 2005.

SZARKA, J. Networking and Small Firms, International Small Business Journal. V. 8, n. 2, p. 10-22, 1990.

TERRA, J.C.; GORDON, C. Portais Corporativos: A revolução na gestão do conhecimento, Tradução de Érica Saubermann Rodrigo Baroni., São Paulo: Negocio Editora, 2002. Original: inglês.

TENÓRIO, F. G. Flexibilização Organizacional: mito ou realidade? Rio de Janeiro: FGV, 2000. $196 \mathrm{p}$.

VERGARA, S. C. Projetos e relatórios de pesquisa em administração. 4. ed. São Paulo: Atlas, 2003. 93 p.

. Métodos de Pesquisa em Administração. São Paulo: Atlas, 2005. 287 p

WENGER, E. C.; SNYDER, W. M. Communities of Practice: the organizational frontier. Harvard Business Review. Jan-Fev, 2000 , p. 139-145.

WHITLEY, R. The fragmented state of management studies: reasons and consequences. Journal of Management Studies, v. 21, n. 3, p. 331-348, 1984.

YIN, R.K. Estudo de caso: planejamento e métodos. Tradução: Daniel Grassi. 3. ed. Porto Alegre: Bookman, 2005. 207 p. 